\title{
Nectaries and male-biased nectar production in protandrous flowers of a perennial umbellifer Angelica sylvestris L. (Apiaceae)
}

\author{
Małgorzata Stpiczyńska • Massimo Nepi • \\ Marcin Zych
}

Received: 6 May 2014/ Accepted: 22 August 2014/Published online: 10 September 2014

(C) The Author(s) 2014. This article is published with open access at Springerlink.com

\begin{abstract}
Nectar is the most common floral pollinator reward. In dichogamous species, floral nectar production rates can differ between sexual phases. We studied the structure of nectaries located on the stylopodium and nectar production in protandrous umbellifer Angelica sylvestris. Our study species produced nectar in both floral sexual phases. Nectar sugar concentration was low (on average $22 \pm 11 \%$, mean $\pm \mathrm{SD}$ ) and the nectar hexose rich and composed of sucrose, glucose, fructose and a small amount of amino acids, including $\beta$-alanine, a non-protein amino acid. Although nectar composition and sugar concentration varied little between floral sexual phases, nectar production showed a threefold reduction during the stigma receptive period. This is in contrast to other studies of Apiaceae that have reported female-biased nectar production, but in the direction predicted by plant sexual selection theory, suggesting that in pollen-unlimited species, floral rewards mainly enhance male reproductive success. The structure of the nectary was similar at the two sexual stages investigated, and composed of a secretory epidermis and several layers of nectariferous and subsecretory parenchyma. The nectary cells were small, had large nuclei, numerous small vacuoles and dense, intensely staining cytoplasm with
\end{abstract}

M. Stpiczyńska · M. Zych

Botanic Garden, Faculty of Biology, University of Warsaw,

Aleje Ujazdowskie 4, 00-478 Warsaw, Poland

M. Nepi

Department of Life Sciences, University of Siena, via Mattioli 4, 53100 Siena, Italy

M. Zych ( $\square)$

University of Warsaw Botanic Garden, Aleje Ujazdowskie 4, 00-478 Warsaw, Poland

e-mail: mzych@biol.uw.edu.pl abundant endoplasmic reticulum, mitochondria and secretory vesicles. They contained abundant resin-like material that may potentially act as defence against microbes. Starch was rarely observed in the nectary cells, occurring predominantly at the female stage and mainly in guard and parenchyma cells in close proximity to stomata, and in subsecretory parenchyma. The main route of nectar release in A. sylvestris seems to be via modified stomata.

Keywords Dichogamy $\cdot$ Fly pollination $\cdot$ Nectar secretion $\cdot$ Nectary structure $\cdot$ Sexual selection . Stylopodium

\section{Introduction}

Dichogamy is widespread in angiosperms (Bertin and Newman 1993; Barrett 2003; Sargent and Otto 2004; Routley et al. 2004; Carlson and Harms 2006). It generally evolved as a mechanism to prevent inbreeding in hermaphroditic plants [but see, e.g., Webb (1981) for other views], and numerous studies indicate that the form of dichogamy varies with pollination mode in angiosperms (Lloyd and Webb 1986; Harder et al. 2001; Mallick 2001; Routley and Husband 2003). According to Sargent and Otto (2004) protandrous species tend to be pollinated by bees or flies, whereas protogynous species, well represented among basal angiosperms (see, e.g., Endress 2010), are predominantly wind or beetle pollinated.

In dichogamous species, floral nectar production rates may differ between sexual phases. According to Carlson and Harms (2006), disproportionate distribution of nectar in the flowers during the male and female phases may reflect a true functional bias towards male or female fitness. Of the 41 species that they list, they noted that nectar 
production rate was greater in the male and female phase for 21 and 20 species, respectively. They also reported that pollinators can recognize any poorly rewarding flowers that occur on plants, with female or male nectar production ratios being as low as 1.2.

Generally, floral nectar is composed of a solution of carbohydrates, namely sucrose and its component monosaccharides-fructose and glucose. They are derived from sucrose transported in phloem sap or are produced directly in the nectary cells (Pacini and Nepi 2007; Nepi et al. 2012). Baker and Baker (1982a, 1983b) recognized four classes of nectar (sucrose dominant, sucrose rich, hexose rich and hexose dominant) according to the ratio by weight of sucrose to the combined hexoses: glucose and fructose. They also suggested that there are co-evolutionary relationships between the sugar proportions in nectar and the types of floral visitors, and high sucrose content in nectar was correlated with pollination by hummingbirds, Lepidoptera and long-tongued bees, whereas high proportions of glucose and fructose were typical of flowers pollinated by passerine birds, flies and short-tongued bees. Nectar also can contain other sugars that are present in trace amounts, e.g., mannose, arabinose, xylose, maltose, melibiose and oligosaccharides such as raffinose, melezitose, stachyose and sorbitol (Nicolson and Thornburg 2007, and references therein). It is worth noting that nectar-dwelling microorganisms can significantly influence/modify nectar-sugar profiles (Canto and Herrera 2012; Vannette et al. 2012; de Vega and Herrera 2013).

Additionally, other less abundant constituents such as amino acids, proteins, organic acids, and some other secondary metabolites such as phenolic compounds, alkaloids or terpenoids were identified in nectar (Baker and Baker 1983b; Nicolson and Thornburg 2007; Nepi 2014). It could not be excluded that pollinators are able to detect differences in the chemical composition of nectar produced by male and female flowers, or in that of flowers at male and female stages. In Cucurbita pepo, female flowers produce significantly more nectar sugar than do male flowers, but both nectars are sucrose rich (Nepi et al. 2001). However, Langenberger and Davis (2002) showed that in protandrous flowers of Carum carvi, the nectar sugar profile differs between sexual stages. Indeed, in this species, nectar was hexose rich in the male stage but hexose dominant during the female phase. Changes in nectar composition may result from nectar resorption. During the stage of active secretion, resorption of particular components ensures nectar homeostasis, but towards the end of the flower life span, nectar constituents are re-utilized (Stpiczyńska 2003a, b; Nepi and Stpiczyńska 2007, 2008).

One of the angiosperm groups where dichogamy (and specifically protandry) is especially common is the carrot family (Apiaceae $=$ Umbelliferae). In some umbelliferous plant species, the overlap of sexual phases in a flower may be substantial, whereas they may be completely separate in others (Bell 1971; Webb 1981). Recently, some authors have demonstrated that, even in some Apiaceae species, pollinators are able to distinguish between floral sexual phases (Schlessman et al. 2004; Davila and Wardle 2007; Zych 2007), and this may be due to, for instance, nectar availability.

In Apiaceae, nectar is secreted by a stylopodium formed from the expanded base of the style. Morphologically, the stylopodium is the swollen ovary roof of an inferior ovary. The gynoecium comprises the two separate style branches. The nectary is also divided into two distinct halves. Erbar and Leins (2010) undertook a comprehensive study of the anatomy and morphology of the stylopodium in Apiales and assessed the taxonomic value of nectary characters for several euasterid II families. Despite the availability of some morphological and anatomical data, studies of nectar secretion in dichogamous species of Apiaceae are uncommon.

Our objectives were to compare the structure of the nectary of Angelica sylvestris L. Apiaceae (= Umbelliferae), a protandrous and andromonoecious plant species (Niemirski and Zych 2011), at two consecutive sexual stages. Since they may differ in secretory activity and, consequently, have the potential to affect nectar both quantitatively and qualitatively, they may influence pollinator behaviour. Thus, we also compared the mass of secreted nectar and its chemical composition during both male and female stages. This, to the best of our knowledge, is the first time for nectary structure and nectar secretion to be quantitatively studied for a member of the Apiaceae at two consecutive sexual floral stages.

\section{Materials and methods}

\section{The plant}

Angelica sylvestris is a member of a large genus of ca. 110 species (Mabberley 2008), and is a common component of the European flora. This species is a herbaceous perennial producing cauline leaves arranged in a rosette, and erect flower stems up to over $2 \mathrm{~m}$ tall (Cannon 1968). The flowers are open and arranged in large multi-layered inflorescences termed compound umbels (Fig. 1a). Petals are greenish white to pinkish, flower symmetry is mostly actinomorphic (Fig. 1b-d), but the outer flowers in umbellets may be slightly zygomorphic. The flowers of $A$. sylvestris are dichogamous and plants generally exhibit strong protandry at the level of the individual flower, the inflorescence and the whole plant, but in some individuals a short overlap in sexual phases is possible within a particular umbel (Niemirski and Zych 2011). 

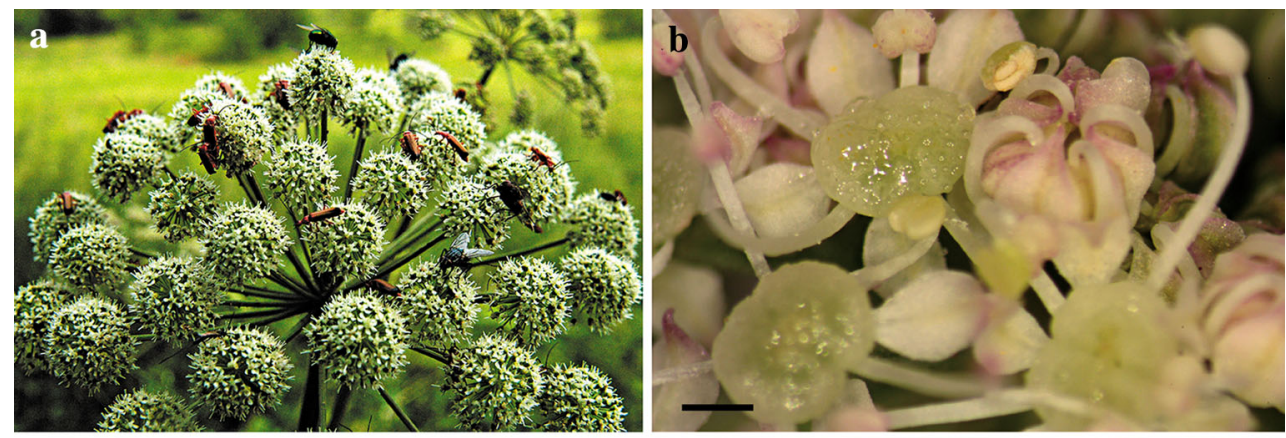

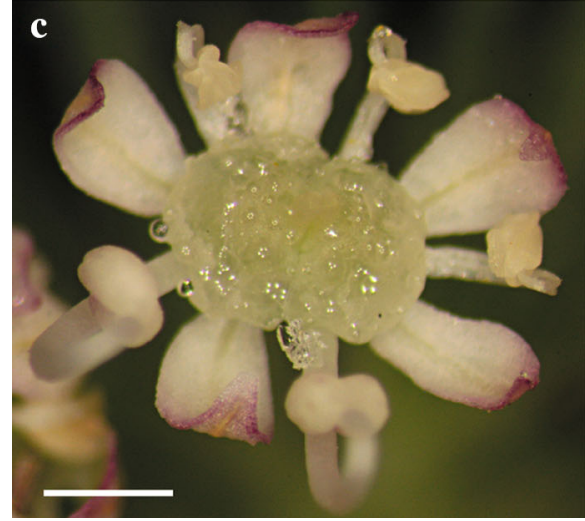

Fig. 1 Inflorescence and flowers of Angelica sylvestris. a Inflorescence with various groups of insect visitors. b Flowers at the beginning of male stage with anthers showing dehiscence and nectar visible upon the surface of stylopodium. c Droplets of copious nectar

Plants used in this study came from natural populations represented in the collection of the University of Warsaw Botanic Garden. Approximately 100 young plant rosettes were removed and transplanted to individual pots of standard garden soil. These were kept in the Botanic Garden of Maria Curie-Skłodowska University in Lublin under prevailing climatic conditions (mean annual temperature $+8.3{ }^{\circ} \mathrm{C}$ and mean annual rainfall $550.6 \mathrm{~mm}$; based on data for the years 1951-2010) until flowering stems appeared. The study took place in 2012 and 2013, and the same plants were used over the 2-year study period. Each season, before flowering commenced, experimental plants were transferred to a closed greenhouse chamber to prevent insect visits. Following flowering, they were again transferred to the garden. Throughout the whole growing season the plants were watered fortnightly with no fertilizer applied.

To determine length of gender stages and the period of secretory activity, umbels (10-15 in bloom) were monitored twice a day using a hand lens $(8-10$ a.m. and 2-3p.m.) throughout the flowering period (02-16 July 2012 and June 30-July18 in 2013). Male stage umbellets from 10 plants were randomly selected (approx. 5 umbellets/ umbel), excised and immediately transferred to the lab for nectar sampling and microscopic observations. Similar

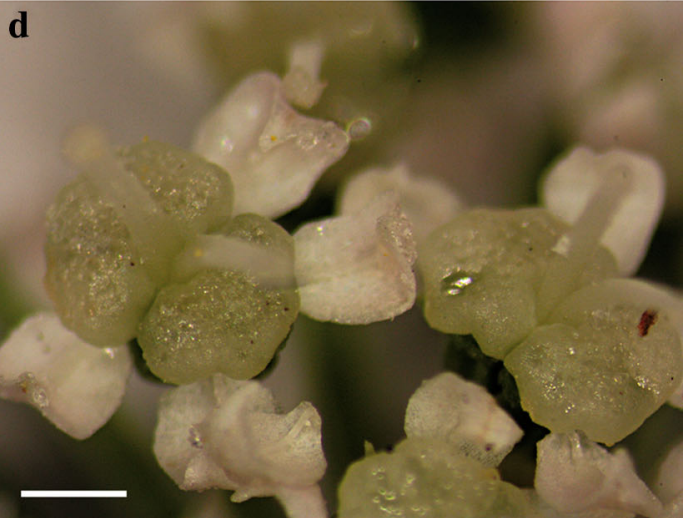

upon stylopodium correspond with location of stomata. d Flowers at female stage with smaller volume of nectar compared with male stage. Scale bars $\mathbf{b}-\mathbf{d}=0.5 \mathrm{~mm}$

procedure was applied to umbellets bearing female stage flowers.

Macroscopic and microscopic observations

The structure of nectaries and the process of nectar secretion were investigated for both male and female sexual stages. During the male stage, anther dehiscence had occurred, but the style and stigma had not expanded (style projected no more than 1-2 $\mathrm{mm}$ above stylopodium). This stage, depending on weather, lasted 3-5 days. Samples for microscopic investigations and for nectar analysis were collected from flowers with all five anthers dehisced. Female stage followed the male stage, and lasted 1-2 days. During the female stage, the two styles and stigmata had completely expanded, but the stamens had completely abscised (Fig. 1b-d). Since the nectar production of female-phase flowers was very low, to collect a sufficiently large and measurable volume of nectar, samples for microscopic investigations and for nectar analysis were collected from flowers on the second day of the female stage.

With the exception of field observations, the presence of nectar on the surface of the stylopodium was also checked for excised flowers using a Nikon SMZ 1000 
stereomicroscope (Nikon Corp., Tokyo, Japan) at the opening bud stage, for male and female stages and at the end of anthesis and flower abscission. At each stage investigated, we used 100 flowers (10 flowers/plant from 10 individuals).

Microscopic observations were made using light microscopy (LM), scanning electron microscopy (SEM) and transmission electron microscopy (TEM). For this purpose, 15 whole gynoecia (with stylopodia) of flowers in the male stage and 15 whole gynoecia of flowers in the female stage, each sampled from five plants, were fixed in $2.5 \%$ glutaraldehyde in cacodylate buffer $(\mathrm{pH} 7.4 ; 0.1 \mathrm{M})$ for $2 \mathrm{~h}$ at $4{ }^{\circ} \mathrm{C}$, washed three times in buffer and post-fixed in $1.5 \%$ osmium tetroxide solution for $1.5 \mathrm{~h}$. The fixed material was then dehydrated using a graded ethanol series, and infiltrated and embedded in Spurr low viscosity resin (Sigma). Following polymerization at $60{ }^{\circ} \mathrm{C}$, sections were cut for TEM at 70-80 nm using a Leica EM UC7 ultramicrotome and glass knife, and examined using a FEI Tecnai Spirit G2 transmission electron microscope equipped with TEM Imaging \& Analysis computer program.

Semi-thin sections $(0.8-1.0 \mu \mathrm{m}$ thick) were prepared for LM. For general histology, these were stained with an aqueous solution of $1 \%$ methylene blue/ $1 \%$ azure II (1:1) for 5-7 $\mathrm{min}$ on a hot plate $\left(60^{\circ} \mathrm{C}\right)$. Insoluble polysaccharides were stained using the PAS reaction by treating the tissue with $1 \%$ periodic acid for $10 \mathrm{~min}$ followed by Schiff's reagent for $20 \mathrm{~min}$ (Jensen 1962).

Histochemical tests were applied in 2012 and 2013 to detect the presence of lipids starch and phenolic compounds in nectary tissue. Approximately, 20 flowers at each stage investigated sampled from 10 plants were used for each treatment. Hand-cut sections of fresh stylopodia were tested for lipids using a saturated ethanolic solution of Sudan III and a $10 \%$ (w/v) aqueous solution of $\mathrm{FeCl}_{3}$ was used to test for catechol-type dihydroxyphenols (Gahan 1984). Also, hand-cut sections were tested for starch using IKI (iodine/aqueous potassium iodide solution). The sections were examined by means of a Nikon E-200 light microscope equipped with a Canon D500 digital camera. Micrometry of the nectary tissue was accomplished using Nikon NIS-Elements AR software.

For SEM, fixed stylopodia were dehydrated and subjected to critical point drying using liquid $\mathrm{CO}_{2}$. They were then sputter coated with gold and examined by means of a Tescan Vega II LS scanning electron microscope at an accelerating voltage of $30 \mathrm{kV}$.

Nectar sampling and nectar analysis

Nectar was sampled for mass and sugar concentration in 2012 and 2013. The samples were collected from flowers in both male and female stages. For this purpose, the entire inflorescences of 10 plants were protected against insect visits by means of nylon mesh (mesh $0.5 \mathrm{~mm}$ ) when all flowers were still in bud. When the flowers reached the appropriate sexual stage, they were excised and immediately transferred to the lab. Using a stereoscopic microscope, the nectar was subsequently sampled using microcapillary pipettes of known mass. A single sample contained nectar collected from 8-10 flowers of the same plant. Thirty samples from each of the two floral sexual phases were collected in 2012 and 2013 (in total 120 samples). To calculate the mass of secreted nectar, the pipettes containing nectar were reweighed using an AS 60/220/C/2 (RADWAG, Radom, Poland) analytical balance. Nectar concentration was determined as follows. Each sample of nectar was collected from 15-25 flowers at the male stage and, owing to the smaller volume of available nectar, from $30-40$ flowers at the female stage. The small volume of nectar produced meant that we were only able to collect 23 samples in 2012 (10 and 13, respectively from male and female flower phases) and 39 in 2013 (30 and 9, respectively from male and female flower phases). The nectar was subsequently expelled onto a refractometer prism RL-4 (PZO, Warszawa, Poland) to record nectar sugar concentration $(\% \mathrm{w} / \mathrm{w})$.

Nectar destined for chemical analysis was collected in 2013 and fixed in $1 \mathrm{ml}$ dehydrated ethanol $99.8 \%$ (POCH, czda-396480111). To determine the composition of nectar sugars during both floral sexual stages, nectar from 50 flowers for each stage of development was collected using micro-pipettes and analysed by isocratic HPLC utilizing LC1 Waters system. A $20 \mu \mathrm{l}$ aliquot of both sample and standard solution was injected. Water (MilliQ, pH 7), with a flow rate of $0.5 \mathrm{ml} / \mathrm{min}$, was used as the mobile phase. Sugars were separated in a Waters Sugar-Pack I column (6.5-300 mm) maintained at $90{ }^{\circ} \mathrm{C}$ and identified by a refractive index detector (Waters 2410). The content of fructose, glucose and sucrose were determined and expressed as the percentage of total sugars.

Amino acid analysis of a $10 \mu \mathrm{l}$ sample of nectar collected from 50-60 flowers for each stage (pooled sample collected from 5 plants, 10-12 flowers/plant) was performed by gradient HPLC using an ion exchange Novapak C18 $(15 \mathrm{~mm} \times 4.6 \mathrm{~mm})$ cartridge, with guard column maintained at $37^{\circ} \mathrm{C}$, and a Waters 470 scanning fluorescence detector (excitation at $295 \mathrm{~nm}$, detection at $350 \mathrm{~nm}$ ). A solvent composed of TEA-phosphate buffer ( $\mathrm{pH}$ 5.0) mixed with a 6:4 acetonitrile-water solution was used as the mobile phase at a flow rate of $1.0 \mathrm{ml} / \mathrm{min}$. According to AccQtag protocol (Waters Corp.), the selected volume of each reconstituted sample was amino acid derivatized (Cohen and Micheaud 1993) with AQC fluorescent reagent and $0.02 \mathrm{M}$ borate buffer ( $\mathrm{pH}$ 8.6). In addition to all the protein amino acids, standards of $\beta$-alanine, citrulline, 
L-homoserine, $\alpha$-aminobutyric acid, $\beta$-aminobutyric acid, $\gamma$-aminobutyric acid, hydroxyproline, ornithine and taurine were used.

\section{Statistics}

Statistica 7.1 (Stat Soft Inc. 2005; Tulsa, OK, USA) was used for all statistical calculations. Two-way mixed model ANOVA was employed for nectar production and concentration data with study year as random factor and floral sexual phase as fixed factor, with post hoc tests applied where appropriate. To obtain normal distribution, the data were square root transformed prior to analysis.

\section{Results}

Morphology and structure of stylopodium

Stylopodia (gynoecial nectaries) of A. sylvestris at both the investigated stages were pale creamy green in colour and did not contrast with that of petals and stamens. The nectary at the male stage measured, on average, $0.65 \times 1.0 \mathrm{~mm}$, whereas at the female stage, it was larger, of average dimensions $1.5 \times 9.8 \mathrm{~mm}$.

Nectar appeared upon the stylopodium concomitantly with the dehiscence of the anthers and was generally present throughout the lifespan of the flower (Fig. 1b-d). At the male stage, large droplets of nectar accumulated close to secretory stomata (Fig. 1c), but during the female phase, traces of hardly accessible, viscous and almost solid nectar only were frequently observed, as a thin film overlying the stylopodium (Fig. 1d). In both investigated stages, the surface of the stylopodium was undulate and slightly raised centrally at the base of the styles. The stomata were sunken in epidermal depressions distributed uniformly over the surface of the gland (Fig. 2 a-d). The guard cells had a smooth cuticle, in contrast to epidermal cells, which had a striate cuticle, but the cuticular ridges did not follow any regular pattern (Fig. 2d-f). Between the ridges, small pores were visible in the cuticle (Fig. 2d). Deposits of material (probably secretory residues) were present on the surface of epidermal cells. Such deposits were more frequently seen at the female stage (Fig. 2f).

Microscopic observations indicated that, in general, the structure of the stylopodium was similar at both male and female stages (Figs. 3a-h, 4a-f). The gland consisted of a single-layered epidermis, 3-5 layers of secretory parenchyma cells and 4-9 layers of subsecretory parenchyma cells. Rectangular epidermal cells measured $22.5 \times$ $16.5 \mu \mathrm{m}$, on average. The periclinal cell walls of epidermal cells $(0.6 \mu \mathrm{m}$ thick, on average $)$ were thicker than the radial walls, the outer cell walls having a cuticle some
$0.1 \mu \mathrm{m}$ thick, on average. In the epidermis starch grains occurred almost exclusively in the guard cells, and only sporadically in regular epidermal cells (Figs. 3h, 4e), and copious resin-like deposits were observed at both sexual stages. These stained with methylene blue-azure II, but neither stained for lipids with Sudan III nor for polyphenolic substances with $\mathrm{FeCl}_{3}$.

Beneath the secretory parenchyma were cells with thin cellulose cell walls $(0.2 \mu \mathrm{m}$ thick, on average) and small intercellular spaces. Secretory parenchyma cells were usually smaller than epidermal cells (measuring $11.28 \times 14.49 \mu \mathrm{m}$ at male and $13.00 \times 15.85 \mu \mathrm{m}$ at female stages). A large nucleus and usually intensely staining cytoplasm containing several small vacuoles were present (Figs. 3b, f, g, 4b). At the female stage, there was a significant increase in the size of vacuoles present in secretory parenchyma cells and in the occurrence of plasmolysis (Fig. 4c, f). At both sexual stages, epidermal and secretory parenchyma cells in the proximity of stomata frequently collapsed, and here, accumulation of resinaceous material was observed (Figs. 3g, 4f). Starch grains were seen in secretory parenchyma cells close to stomata (including collapsed cells, Fig. 4f), as well as subsecretory parenchyma cells (Fig. 4b, e, f). Subsecretory parenchyma cells were larger in the female stage than the male stage (on average $32.66 \times 17.0 \mu \mathrm{m}$ and $28.64 \times 11.36$, respectively), and also had larger vacuoles.

The ends of vascular bundles embedded in the subsecretory parenchyma consisted of xylem and phloem strands, but vascular bundles did not penetrate into the secretory tissue (Fig. 3a-c). Oil ducts occurred in the subsecretory parenchyma (Fig. 3g).

TEM observations revealed that the cytoplasm of secretory cells was electron dense and contained abundant mitochondria and several small vacuoles lacking visible content (Fig. 5a-d). Dictyosomes were rarely seen (Fig. 5b). Numerous profiles of smooth endoplasmic reticulum were frequently present and were either closely associated with plastids (Fig. 5a) or formed dilated cisternae (Fig. 5d). Plastids contained an electron dense stroma, poorly developed internal membranes and only occasionally contained starch grains (Fig. 5a, c, d). Plastoglobuli were rarely observed. The cells of subsecretory parenchyma (Fig. 5e-f) usually contained one large vacuole and thin parietal cytoplasm. At the female stage, plastids frequently contained starch grains (Fig. 5f). This tissue contained well-developed intercellular spaces. Plasmodesmata were present in the cell walls of secretory and subsecretory parenchyma.

\section{Nectar production}

Under our glasshouse conditions, flowers of A. sylvestris produced minute quantities of nectar in both male and 

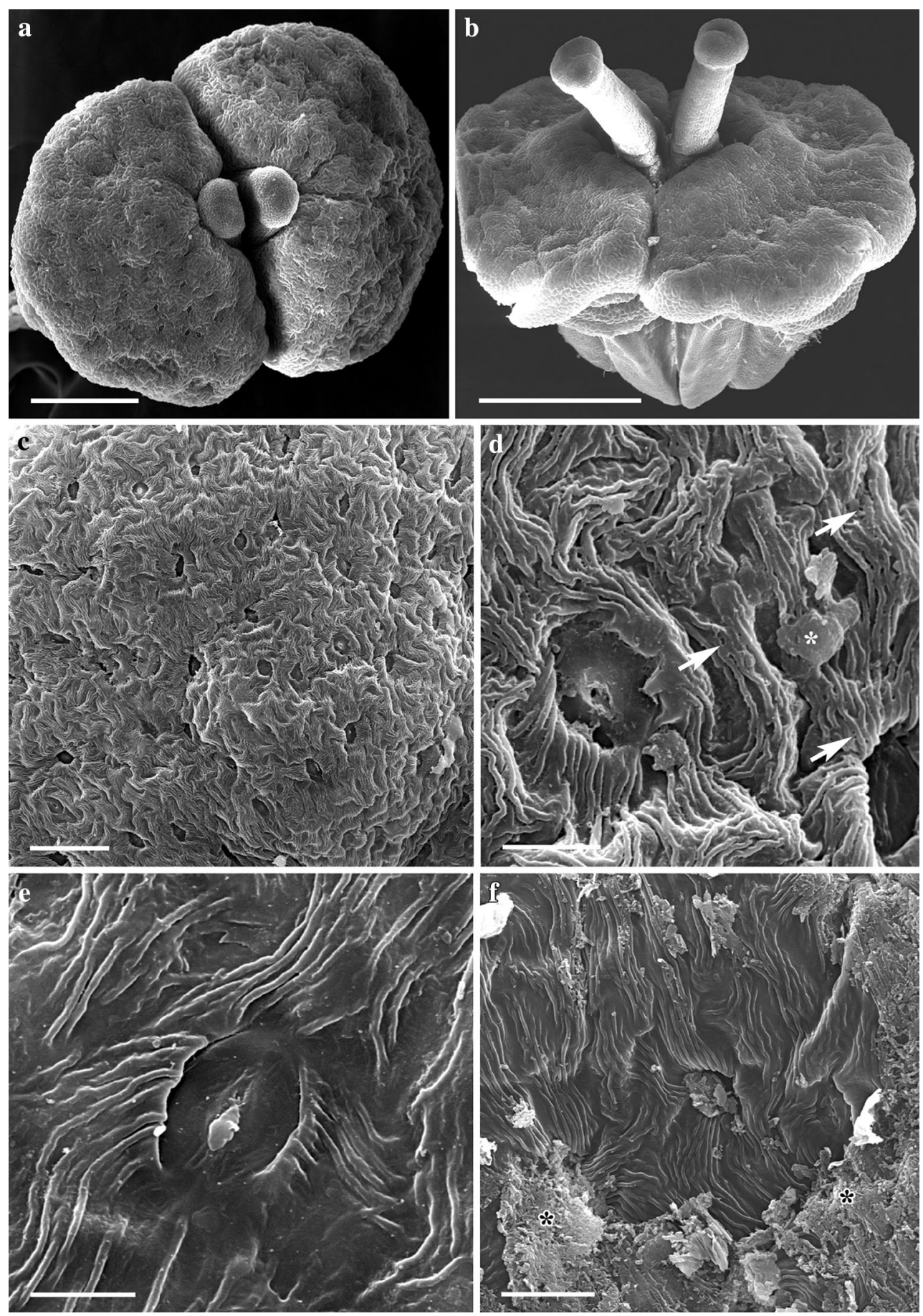

Fig. 2 Surface of stylopodium, SEM. a Stylopodium at male stage. Scale bar $=200 \mu \mathrm{m}$. b Stylopodium at female stage with expanded styles. Scale bar $=500 \mu \mathrm{m}$. c Stomata uniformly distributed in epidermis. Scale bar $=50 \mu \mathrm{m}$. d Epidermal cells with secretory

female phase flowers. Male phase flowers produced over three times more nectar mass than female phase flowers $(0.695 \pm 0.468$ vs. $0.202 \pm 0.193 \mathrm{mg}$ per 10 flowers, mean \pm SD calculated across both study years, $P<0.001$, stomata, remnants of secretion (asterisk) and pores between cuticular ridges (arrows). e Stoma with released droplet of nectar. d, e Scale bars $=10 \mu \mathrm{m}$. $\mathbf{f}$ Remnants of secretion (asterisks) on the surface of nectary at female stage. Scale bar $=20 \mu \mathrm{m}$

two-way mixed model ANOVA on square root transformed data; see Table 1) and, for a given flower sexual phase, mass of nectar produced was constant for both study seasons (Fig. 6). 

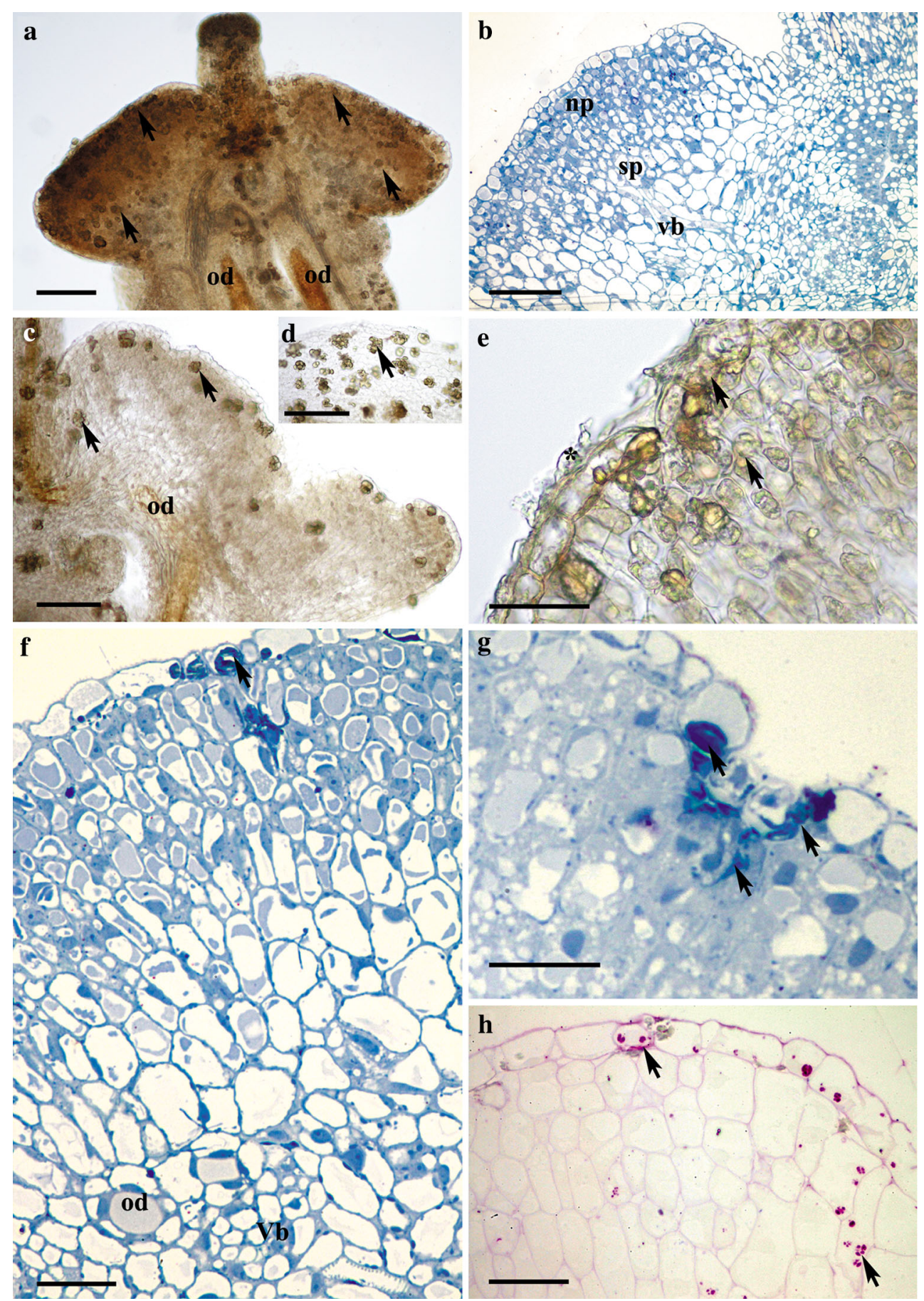

Fig. 3 Stylopodium at male stage, LM. a Hand-cut longitudinal section of whole stylopodium showing distribution of secretory tissue, resin-like material and main vascular bundles. Scale bar $=100 \mu \mathrm{m}$. b Epidermis, secretory parenchyma and subsecretory parenchyma with vascular bundle. c Nectary tissue with resin-like material (arrows) in epidermal and subepidermal cells, together with vascular bundles and oil ducts. b, c Scale bar $=50 \mu \mathrm{m}$. d Surface section with numerous resin-like deposits in epidermal cells (arrow). Scale bar $=100 \mu \mathrm{m}$. e Resin-like deposits in epidermis and secretory parenchyma (arrows). Residues of secretion (asterisk) on the surface of epidermis close to the stoma. Scale bar $=25 \mu \mathrm{m}$. f Longitudinal section of nectary tissue with oil duct and vascular bundle in subsecretory parenchyma. Scale bar $=25 \mu \mathrm{m}$. g Resin-like material that stains deep blue with methylene-azure II deposited in epidermal cells and secretory parenchyma cells close to stoma. Scale bar $=20 \mu \mathrm{m}$. h Infrequent starch grains (arrows) present in epidermal cells and secretory parenchyma (PAS) Scale bar $=25 \mu \mathrm{m} . n p$ Nectary parenchyma, od oil duct, $s p$ sub-nectary parenchyma, $v b$ vascular bundle 


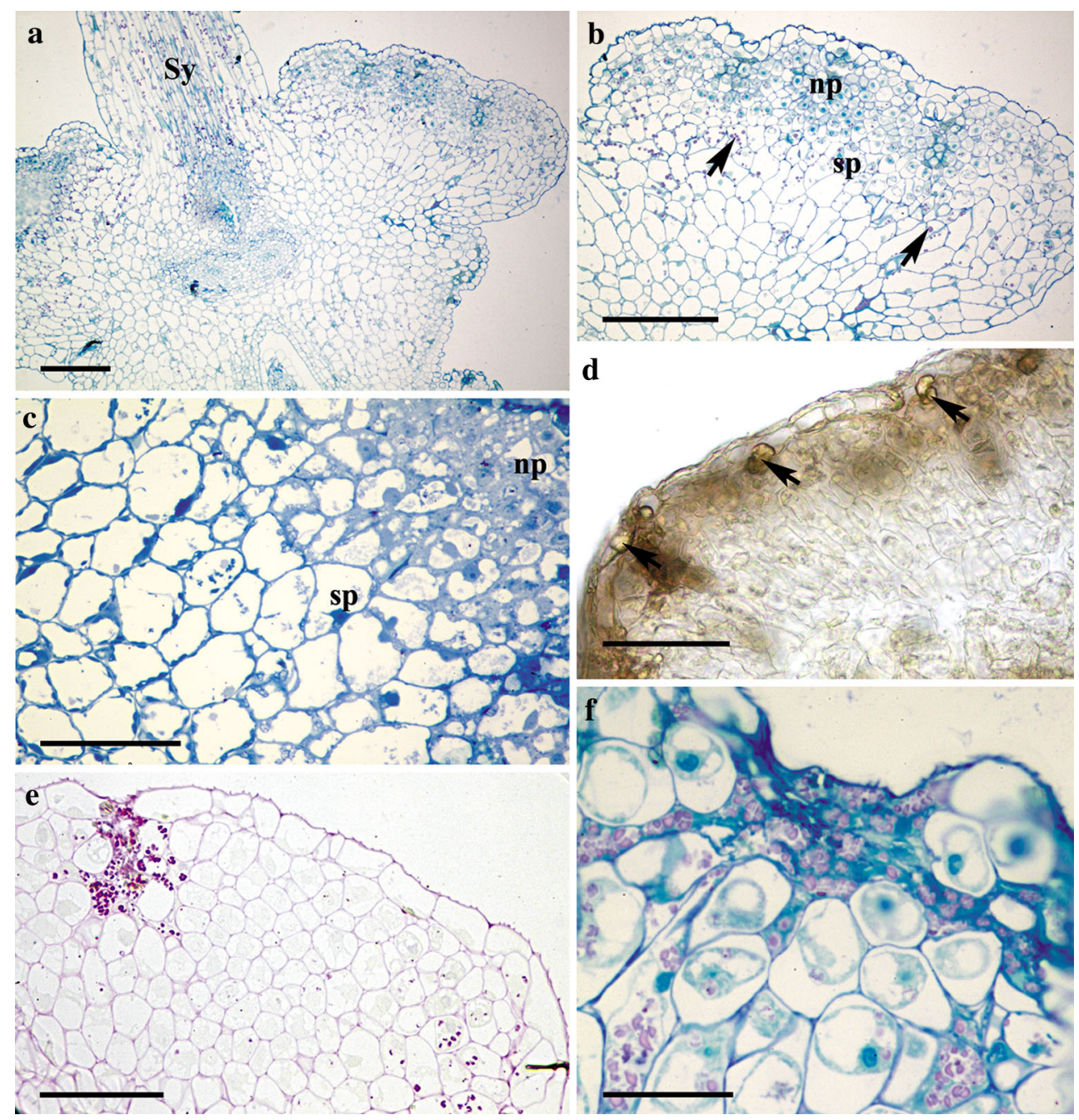

Fig. 4 Longitudinal sections of the nectary at female stage, LM. a Section of stylopodium. b Detail of stylopodium showing distribution of starch grains in subsecretory parenchyma (arrows) following staining with methylene blue-azure II + PAS. a, b Scale bar $=100 \mu \mathrm{m}$. c Cells of nectary parenchyma and sub-nectary parenchyma with large, centrally located vacuoles. Scale bar $=35 \mu \mathrm{m}$. d Resin-like deposits in epidermal and nectary

\section{Nectar sugar concentration and composition}

Angelica sylvestris flowers produced rather dilute nectar (average total sugar concentration $22 \pm 11 \%$, mean $\pm \mathrm{SD}, N=62$; data pooled over two study seasons and flower sexual phases), and we found no significant differences in nectar sugar concentration between umbel sexual phases (Fig. 7). We recorded, however, a significant effect of study year and decline in nectar sugar concentration in 2013, compared with data from 2012. This was especially pronounced in female phase flowers (mean \pm SD: $29 \pm 15 \%$ vs. $15 \pm 8 \%, P=0.012$, Twoway ANOVA see Table 1). parenchyma cells (arrows) close to stomata. e Starch accumulated in nectary parenchyma near stoma following staining with PAS. d, e Scale bar $=50 \mu \mathrm{m}$. f Collapsed cells of epidermis and nectary parenchyma containing starch grains following staining with methylene blue-azure II + PAS. Scale bar $=20 \mu \mathrm{m}$. $n p$ Nectary parenchyma, $s p$ sub-nectary parenchyma, Sy style

Nectar of A. sylvestris was rich in hexose and the relative percentages of sucrose, glucose and fructose were similar in the two flower sexual phases $(14,31,55$ and 12 , 28,58 for male and female phase respectively). The nectar also contained some amino acids. The total amino acid concentration of nectar was 0.254 and $0.043 \mu \mathrm{mol} \mathrm{ml}^{-1}$ in male and female phase, respectively (Table 2). A wider array of amino acids was detected in the nectar from male phase flowers: 12 protein amino acids and 7 non-protein amino acids whilst only 6 and 4 were present, respectively, in the female phase (Table 2). Also, the relative abundance of amino acids was different between the two sexual phases: in the nectar from male phase flowers, the most 

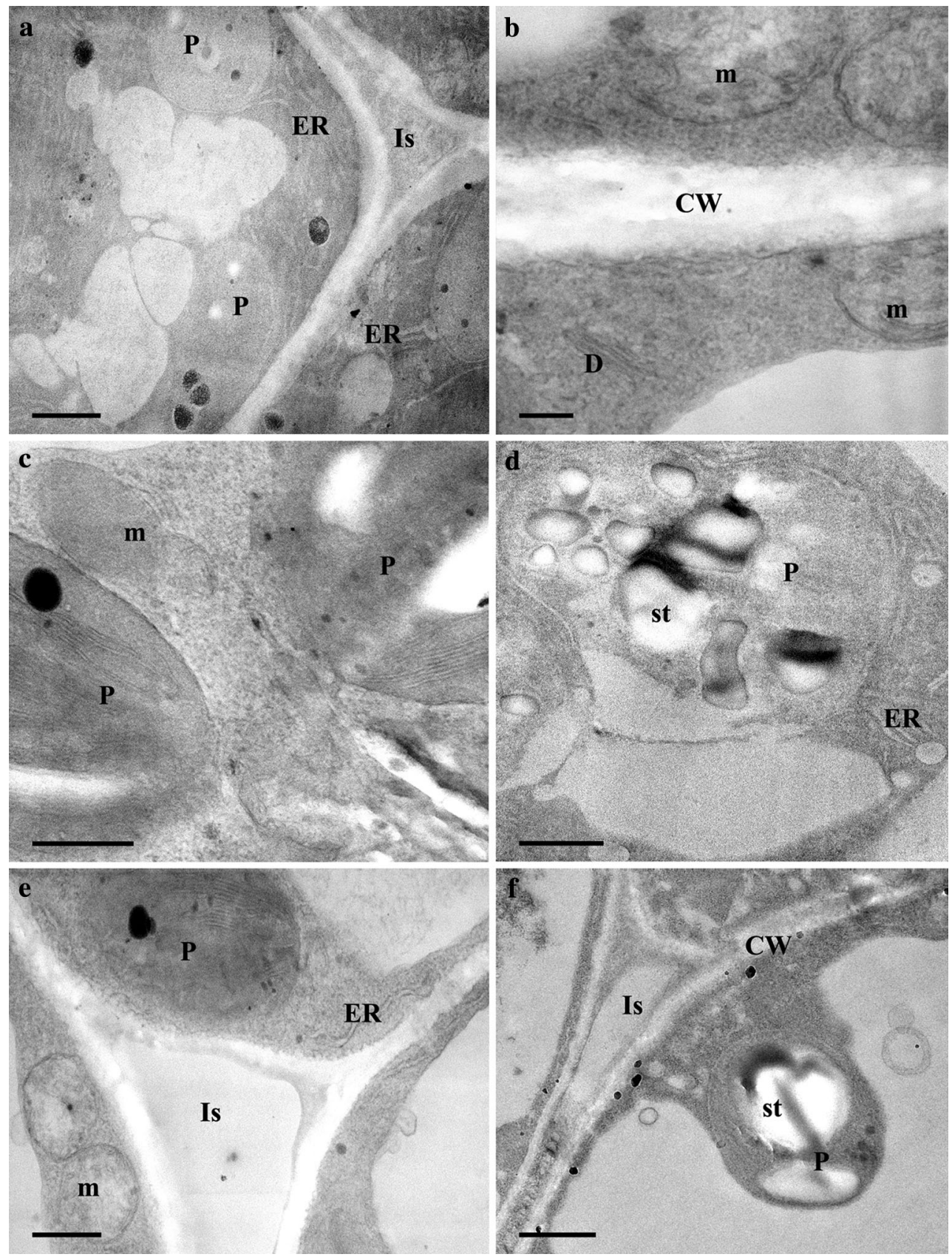

Fig. 5 Ultrastructure of nectary cells, TEM. a-c and e, male stage, $\mathbf{d}$ and $\mathbf{f}$, female stage. a Nectary cell with numerous ER profiles and starchless plastids. Scale bar $=1 \mu \mathrm{m}$. b Mitochondria gather near cell wall. Scale bar $=0.2 \mu \mathrm{m}$. $\mathbf{c}$ Plastids with electron dense stroma and minute starch grains. Scale bar $=0.5 \mu \mathrm{m}$. $\mathbf{d}$ Nectary cell with profiles of ER and plastid containing starch. Scale bar $=1 \mu \mathrm{m}$ e Sub-nectary

abundant amino acids were serine and leucine (both around $15 \%$ of the total amino acid concentration), whilst in female phase flowers, they were proline, leucine, $\beta$-alanine (30, 16 and $14 \%$, respectively). parenchyma cells with large intercellular space and starchless plastid. Scale bar $=0.5 \mu \mathrm{m}$. f Sub-nectary parenchyma cell with parietal cytoplasm and plastid containing starch. Scale bar $=1 \mu \mathrm{m}$. CW Cell wall, $D$ dictyosome, $E R$ endoplasmic reticulum, $I s$ intercellular space, $m$ mitochondrion, $P$ plastid, st starch

\section{Discussion}

Despite differences in the secretory activity and size of the stylopodium of $A$. sylvestris (an increase in size during the 
Table 1 Results of two-way mixed model analysis of variance (ANOVA) on nectar production (mass of secreted nectar) and sugar concentration in flowers of Angelica sylvestris

\begin{tabular}{lrrrrr}
\hline Source & df & $\begin{array}{l}\text { Sum of } \\
\text { squares }\end{array}$ & $\begin{array}{l}\text { Mean } \\
\text { square }\end{array}$ & \multicolumn{1}{l}{$F$} & $P$ \\
\hline Nectar production & & & & & \\
$\quad$ Year & 1 & 0.2231 & 0.2231 & 2.9682 & 0.088 \\
Sex & 1 & 4.9473 & 4.9473 & 65.8300 & 0.000 \\
Year $\times$ sex & 1 & 0.1340 & 0.1340 & 1.7829 & 0.184 \\
Error & 116 & 8.7177 & 0.0752 & & \\
Sugar concentration & & & & & \\
Year & 1 & 6.5250 & 6.5250 & 6.2120 & 0.016 \\
Sex & 1 & 0.1090 & 0.1090 & 0.1036 & 0.749 \\
Year $\times$ sex & 1 & 7.1500 & 7.1500 & 6.8067 & 0.012 \\
Error & 58 & 60.9250 & 1.0500 & & \\
\hline
\end{tabular}

Before calculations, data were square root transformed to obtain normal distribution. 'Year' (random factor) denotes the effect of study year (2012 vs. 2013); 'Sex' (fixed factor) the effect of umbel sexual phase (male vs. female)

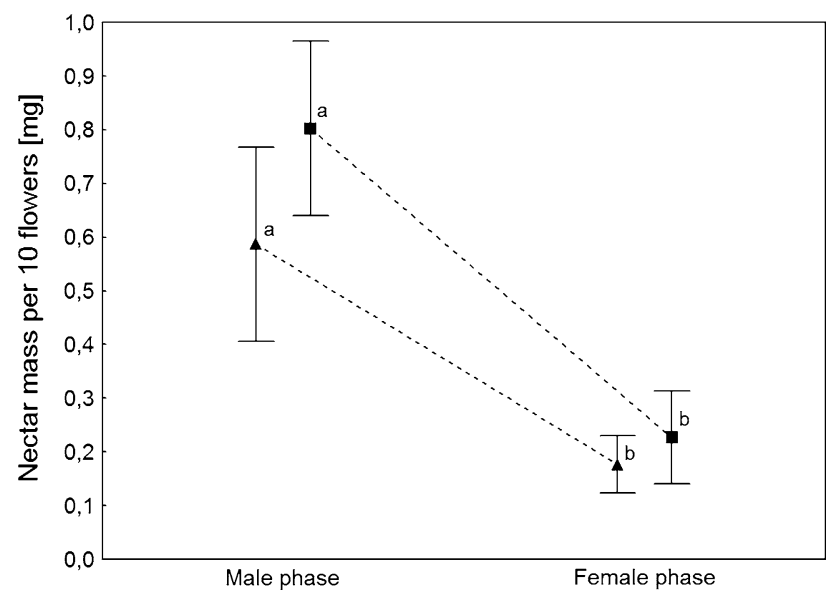

Fig. 6 Average nectar mass (mg) in male and female phase flowers of Angelica sylvestris over two growth seasons (2012 triangles, 2013 squares); surveyed were first-order (main) umbels. Error bars indicate 0.95 confidence interval of the mean. Means with various letters are different at $P<0.001$ (HSD Tukey's post hoc test)

female stage was correlated with enlargement of the entire ovary), the structure of the nectary was similar for the two investigated sexual stages. The nectary was composed of a secretory epidermis and several layers of nectariferous and subsecretory parenchyma. Such organization reflects the general pattern of anatomical structure of nectaries in Apiaceae (Erbar and Leins 2010), as well as that of many other previously investigated taxa (Nepi 2007, and references therein). Additionally, the nectary cells of $A$. sylvestris share many ultrastructural features with the mesenchymatous nectaries of other plant species in that they are small, have large nuclei, numerous small vacuoles

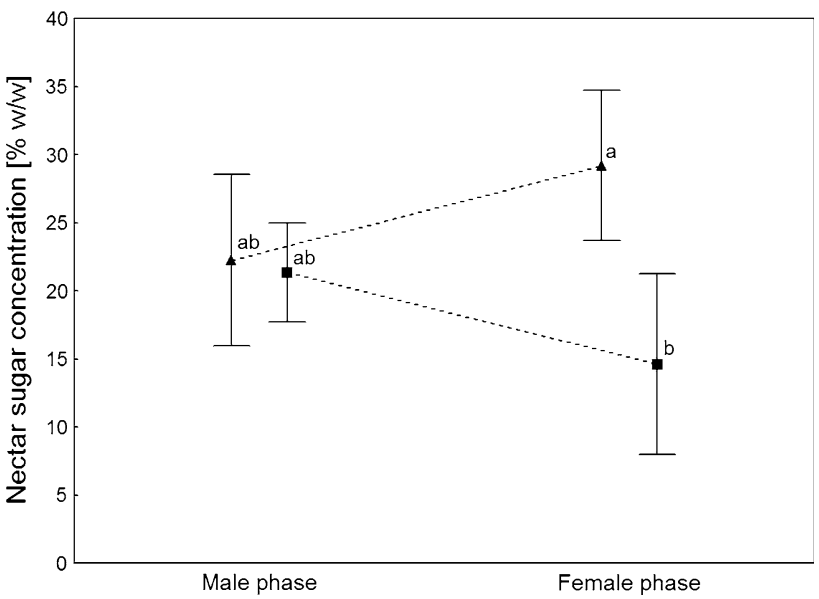

Fig. 7 Average nectar sugar concentration $[\% \mathrm{w} / \mathrm{w}]$ in male and female phase flowers of Angelica sylvestris over two growth seasons (2012 triangles, 2013 squares); surveyed were first-order (main) umbels. Error bars indicate 0.95 confidence interval of the mean. Means with various letters are different at $P<0.02$ (Tukey's post hoc test for uneven $N$ )

Table 2 Concentration and relative percentages of amino acids in the nectar from male- and female-phase flowers of Angelica sylvestris

\begin{tabular}{|c|c|c|c|c|}
\hline & \multicolumn{2}{|c|}{ Concentration } & \multicolumn{2}{|c|}{ Relative (\%) } \\
\hline & M & $\mathrm{F}$ & M & $\mathrm{F}$ \\
\hline serine & 0.041 & 0.004 & 15.698 & 9.302 \\
\hline glycine & 0.007 & & 2.713 & \\
\hline histidine & 0.040 & & 15.504 & \\
\hline arginine & 0.007 & & 2.713 & \\
\hline threonine & 0.013 & & 5.039 & \\
\hline alanine & 0.021 & 0.002 & 8.269 & 4.651 \\
\hline proline & 0.026 & 0.013 & 9.981 & 30.233 \\
\hline valine & 0.004 & 0.002 & 1.550 & 4.651 \\
\hline lysine & 0.016 & & 6.202 & \\
\hline isoleucine & 0.003 & & 1.163 & \\
\hline leucine & 0.008 & 0.007 & 3.101 & 16.279 \\
\hline phenylalanine & 0.009 & 0.004 & 3.295 & 8.140 \\
\hline glutamine & 0.010 & & 3.876 & \\
\hline asparagine & 0.012 & 0.003 & 4.651 & 6.977 \\
\hline taurine & 0.002 & & 0.775 & \\
\hline citrulline & 0.007 & 0.001 & 2.713 & 2.326 \\
\hline$\beta$-alanine & 0.019 & 0.006 & 7.235 & 13.953 \\
\hline ornithine & 0.005 & 0.001 & 1.938 & 2.326 \\
\hline$\beta$-amino butyric acid & 0.009 & & 3.391 & \\
\hline Total amino acids & 0.254 & 0.043 & & \\
\hline
\end{tabular}

Non-protein amino acids are in italics. Concentrations are expressed as $\mu \mathrm{mol} / \mathrm{ml}$

$M$ male phase, $F$ female phase

and dense, intensely staining cytoplasm with abundant endoplasmic reticulum, mitochondria and secretory vesicles. However, contrary to the majority of nectaries 
investigated to date, starch was rarely observed in the nectary cells of $A$. sylvestris, occurring mainly in guard cells and parenchyma cells in close vicinity to the stomata, as well as in subsecretory parenchyma. Furthermore, starch was observed predominantly at the female stage. Perhaps starch was deposited in response to nectar resorption at the female stage, and utilized in ovary/ovule development. Incorporation of sucrose from resorbed nectar into starch grains in developing ovaries and ovules has previously been observed, e.g., in Platanthera chlorantha (Stpiczyńska 2003a, b). However, starch usually accumulates in nectary cell plastids at the pre-secretory stage, and plays an important role in nectar production (Nepi 2007; and references therein). According to the mechanism postulated by Ren et al. (2007) for Nicotiana, starch stored in amyloplasts at the pre-secretory stage is hydrolysed during the secretory stage and serves both as a source of carbohydrate for nectar and as a source of energy to pump sugars from the phloem into the nectary. Since starch was not abundant in the nectary cells of A. sylvestris, the main source of sugars secreted in the nectar was probably the phloem sap. Vascular bundles do not penetrate secretory tissue in $A$. sylvestris because vascular strands end in the subsecretory parenchyma and consequently, sugars are probably transported along the apoplast and/or the symplast of nectary tissue, as in the nectaries of other investigated taxa (Nepi 2007; Pacini and Nepi 2007; Vassiliev 2010; Heil 2011).

The nectary epidermal and subepidermal parenchyma cells of A. sylvestris, like those of other species, have thin cellulosic walls, and such cell walls may serve as an apoplastic route for nectar transport within nectary tissue, especially where cutinized barriers that could inhibit nectar flow are absent from the wall. Plasmodesmata connecting secretory cells and subsecretory parenchyma cells are common, and they may facilitate additional transport of nectar along the symplast. These models of pre-nectar movement along the apoplast and/or symplast within secretory tissue, as well as the process of secretion, have been proposed by several researchers (Gunning and Hughes 1976; Kronestedt-Robards and Robards 1991; Nepi 2007; Vassiliev 2010; Heil 2011). According to Bush (1999), Williams et al. (2000) and Lemoine (2000), both pathways of sucrose transport may operate in the same plant. Sucrose may be imported into sink cells from the apoplast, either directly by sucrose transporters or by monosaccharide transporters following its hydrolysis to glucose and fructose by cell wall invertase. Within the protoplasts of nectary cells, nectar undergoes a final modification and is subsequently secreted into the periplasmic space. Since, in the nectary cells of A. sylvestris, numerous mitochondria are present, and secretory vesicles are not usually present near the plasmalemma, it is probable that sugars are actively transported across the plasmalemma, and that an eccrine mode of secretion operates here, as found in the nectaries of many other plant species (Kronestedt-Robards and Robards 1991; Fahn 2000; Nepi 2007; Vassiliev 2010; Abedini et al. 2013). Once secreted by the protoplast, nectar passes across the cell wall and can flow onto the surface of the nectary via intercellular spaces and modified stomata, a permeable cuticle or via pores/cracks in the cuticle. In A. sylvestris, modified stomata appear to be the main route of nectar release, despite the presence of some cuticular pores, as observed by SEM. Moreover, stomata may provide a means for the resorption of nectar that was not collected by pollinators during the female stage, since accumulation of starch at this stage was observed in cells close to the stomata. Nectar resorption via nectarostomata was confirmed for Cucurbita pepo by means of radiolabelled sucrose (Nepi and Stpiczyńska 2007) and resorption of sugars following each male and female stage, together with the presence of stomata in the epidermis covering the stylopodium, was reported by Langenberger and Davis (2002) for Carum carvi.

The nectary cells of $A$. sylvestris contain abundant resinlike material that may act as a defence against microbial attack because plant resins are rich in terpenoids (Langenheim 2003). Nectar, especially in open-type nectaries, is an excellent culture-medium for the growth of fungi and bacteria, and contamination of nectar by micro-organisms is relatively common. The possibility that nectar microorganisms, probably frequent in nectar secreted by the open-type nectary found in Apiaceae, cannot be excluded and these may alter the nectar sugar profile, causing a decrease in sucrose and an increase in fructose and sucrose concentrations. Also it has been reported that proteins present in nectar can function as protection against infections by micro-organisms (Nicolson and Thornburg 2007; Nepi et al. 2011). However, similar resin-like material was not reported for the nectaries of those members of Apiaceae investigated by Erbar and Leins (2010).

Like the nectar sugar content of most angiosperms (Willmer 2011), that of A. sylvestris is composed of three main constituents, sucrose, glucose and fructose. According to the classification of Baker and Baker (1983a), it is hexose rich [sucrose:(glucose + fructose) ratio of 0.16]. When compared with the results obtained for other closely related plant species, a low proportion of sucrose, resulting in hexose-rich or hexose-dominant nectars seems a common feature of Apiaceae (Percival 1961; Langenberger and Davis 2002; Petanidou et al. 2006). This feature is also found in other plants with shallow, bowl-shaped flowers and exposed nectaries, and may be an adaptation to prevent the rapid evaporation of nectar (Corbet 1978; Vezza et al. 2006). It is interesting to note that the non-protein amino acid $\beta$-alanine, the most ubiquitous amino acid in the 
nectar of $A$. sylvestris, may represent up to $42 \%$ of the total amino acid content. This feature seemingly contradicts what would be expected. Given the alimentary value of nectar, one would expect protein amino acids to occur more frequently and abundantly than their non-protein counterparts. Recently, it was proposed that the non-protein amino acids of nectar play a role in modifying the foraging behaviour of insects by affecting the regulation of their nervous systems and thus promoting flight (Nepi 2014).

Our study species produced nectar during both flower sexual phases, as commonly found in other dichogamous species of Apiaceae (Koul et al. 1989, 1993; Davila and Wardle 2002; Langenberger and Davis 2002; Pérez-Bañón et al. 2007; Zych 2007). Differences in nectar sugar concentration between years (a decrease noted particularly in female stage) were probably caused by weather conditions. However, nectar composition was relatively constant for male and female floral phases, in contrast to Carum carvi growing in glasshouse conditions, where an increase in the ratio of hexoses was found during the female phase (Langenberger and Davis 2002). Likewise, nectar production in A. sylvestris is clearly gender biased. This phenomenon, usually thought to be driven by sexual selection or inbreeding avoidance, has already been reported for members of several other dichogamous plant families (Carlson and Harms 2006), including both protandrous representatives of the Apiaceae and closely related Araliaceae. Remarkably, to date, only female-biased cases have been described in the latter groups (Koul et al. 1993; Langenberger and Davis 2002; Pei et al. 2011). Here, however, for the first time, we present quantitative analyses of male-biased nectar production for a member of Apiaceae. Among umbellifers, this phenomenon has previously been recorded only once (Pérez-Bañón et al. 2007), and that for Daucus carota subsp. commutatus. Since pollen is utilized by the most important pollinators of umbelliferous plants, namely flies and bees (Koul et al. 1993; Langenberger and Davis 2002; Zych 2007), Pei et al. (2011) have argued that in the absence of pollen, female-biased nectar secretion can be predicted for all protandrous flowers as a compensatory mechanism. This phenomenon is thought also to occur in members of other plant families, but this seems not to be the case for our study species. One of the possible explanations is that it occurs most frequently in pollen-limited species (such as Polemonium caeruleum studied by Zych et al. 2013), and percentage seed set of $A$. sylvestris is usually $100 \%$, at least in part of its geographic range (M. Zych, unpublished data), which is indicative of a lack of pollen limitation. In such cases, floral rewards should mainly enhance male reproductive success, as suggested by Thomson et al. (1989). In A. sylvestris, this is achieved by more than a threefold increase in nectar production during the pollen presenting phase, and, as found for another umbelliferous species, Smyrnium olusatrum, this may be linked to a greater investment in male functions (Lovett Doust and Harper 1980). This is in accordance with the sexual selection theory in plants (see, e.g., Aizen and Basilio 1998; Carlson and Harms 2006; Carlson 2007) and may further influence insect behaviour and favour a more rewarding male phase, as was observed for D. carota subsp. commutatus (Pérez-Bañón et al. 2007). Preferences towards male phase umbels have been described for several other umbelliferous species (Lindsey and Bell 1985; Schlessman et al. 2004; Davila and Wardle 2007; Zych 2007), but this is not the rule for the entire family (see, e.g., Zych et al. 2014), and, specifically, was not detected for A. sylvestris (Niemirski and Zych 2011; Zdral and Zych 2012). The latter seems rather surprising, as during the male phase of $A$. sylvestris flowers, insects are offered abundant pollen and nectar, but during the female phase, only traces of hardly accessible, viscous and almost solid nectar are present, which appear in the form of a thin film overlying the stylopodium, thus resembling a lollypop. Such presentation of nectar during the female phase may reduce visits by certain insect species (phenotypic filter, $c f$. Ollerton et al. 2007), since in this case, floral rewards seem especially difficult to gather by insects other than flies with a cushion-like labium. In terms of its pollination system, $A$. sylvestris is regarded a supergeneralist (Olesen et al. 2007), since its protandrous flowers are visited by a wide range of insects representing several taxonomic orders (Ellis and Ellis-Adam 1993; Zych et al. 2007; Niemirski and Zych 2011). It has open, dish-shaped flowers with no additional morphological adaptations that would restrict the access of insect visitors to floral rewards. However, recent analysis of insect effectiveness revealed that the flowers are mainly pollinated by a narrow assemblage of muscoid and syrphid flies that constituted $85-90 \%$ of visitors to either sexual phase of $A$. sylvestris umbels in the population studied by Niemirski and Zych (2011). These authors found that insects did not prefer male over female phase umbels. Lack of any preferences towards either umbel sexual phase (in both cases, measured in terms of visit frequency) was later reported also by Zdral and Zych (2012) for another population of $A$. sylvestris visited mainly by beetles.

As suggested by Niemirski and Zych (2011), umbel sexual phases could be distinguished if the insects were able to detect differences between pollen presenting and stigma receptive flowers. In the case of flies, visual clues, and especially yellow colouration (the most common colour for pollen) seem to play an important role in the attraction of insects to flowers (Lunau 2000). For instance, as shown by Lunau et al. (2005), the syrphid fly Eristalis tenax can distinguish between small yellow spots contrasting with other colours, an ability that, according to 
Niemirski and Zych (2011), may be responsible for recognizing the pollen presenting phase in some umbelliferous plants with yellow anthers and pollen, e.g., Heracleum sphondylium. Therefore, in A. sylvestris, where stylopodia, petals, anthers and pollen grains are rather uniformly greenish yellow or cream in colour, the pollination system may involve some elements of floral deception because pollinators and floral visitors cannot distinguish between male and female phase flowers. On the other hand, the quality of a floral visitor may be measured, not only in terms of the frequency of its visits, but also in terms of the duration of the visit and the number of flowers visited in a single bout (especially as in Apiaceae an umbellet or even the whole compound umbel is regarded as a unit of pollination; Bell 1971). Furthermore, the total number of pollen grains picked up by a pollinator should be positively correlated with the number of flowers visited on a plant (Zimmerman 1988). If the above is true, i.e., insects may be able to detect the amount of reward only while landing on a flower, floral visitors should stay longer/visit more umbellets per inflorescence on male phase umbels. In doing so they would acquire more pollen, which benefits male function. On the other hand, insects should depart earlier from/visit fewer umbellets of female umbels. Paradoxically, the latter may be still beneficial for female function since, theoretically, several pollen grains suffice for the $100 \%$ seed set of the umbelliferous flowers (there are only two ovules per ovary), and even short visit may result in more than enough pollen being deposited on a stigma for a full seed set. Unfortunately, we do not know of any field data relating to visit duration to A. sylvestris flowers, but results for other umbellifers, e.g., Heracleum sphondylium showed that the number of umbellets visited within a single visit may indeed differ for male and female phase umbels (Zych 2003). On the other hand, however, Zych et al. (2014) did not find such differences for umbelliferous Ostericum palustre.

Last but not least, the level of nectar production bias and expression of dichogamy may also vary between populations of our study plant, depending, e.g., on the level of pollinator availability or identity. All the above indicate the need for further research and show interesting arenas for new studies on these aspects of the pollination biology of umbelliferous plants.

Acknowledgments We are grateful to Agnieszka Krzyk and Włodzimierz Winiarski for help with plant collection in the field; to Dorota Szubierajska (University of Warsaw Botanic Garden) and Grażyna Szymczak (Botanic Garden of the Maria Curie-Skłodowska University in Lublin) for help with plant cultivation; to Magdalena Kamińska for help in nectar sampling, and to Magdalena Włodarska for help in the preparation of microscope slides. The study was financially supported by the research grant 2011/01/B/NZ8/03146 from the National Science Centre, Poland (to MZ and MS).
Open Access This article is distributed under the terms of the Creative Commons Attribution License which permits any use, distribution, and reproduction in any medium, provided the original author(s) and the source are credited.

\section{References}

Abedini M, Movafeghi A, Aliasgharpour M, Dadpour MR (2013) Anatomy and ultrastructure of the floral nectary in Peganum harmala L. (Nitrariaceae). Pl Spec Biol 28:185-192

Aizen MA, Basilio A (1998) Sex differential nectar secretion in protandrous Alstroemeria aurea (Alstroemeriaceae): is production altered by pollen removal and receipt? Amer J Bot $85: 245-252$

Baker HG, Baker I (1983a) Floral nectar sugar constituents in relation to pollinator type. In: Jones CE, Little RJ (eds) Handbook of experimental pollination ecology. Van Nostrand Reinhold, New York, pp 117-141

Baker HG, Baker I (1983b) A brief historical review of the chemistry of floral nectar. In: Bentley B, Elias T (eds) The biology of nectaries. Columbia University Press, New York, pp 126-152

Barrett SCH (2003) Mating strategies in flowering plants: the outcrossing-selfing paradigm and beyond. Phil Trans R Soc B 358:991-1004

Bell CR (1971) Breeding systems and floral biology of the Umbelliferae or evidence for specialization in unspecialized flowers. In: Heywood VH (ed) The biology and chemistry of the Umbelliferae. Academic Press, London, pp 93-107

Bertin RI, Newman CM (1993) Dichogamy in angiosperms. Bot Rev 59:112-152

Bush DR (1999) Sugar transporters in plant biology. Curr Opinion Pl Biol 2:187-191

Cannon JFM (1968) Angelica L. In: Tutin TG et al (eds) Flora Europaea, vol 2. Cambridge University Press, Cambridge, pp 357-358

Canto A, Herrera CM (2012) Micro-organisms behind the pollination scenes: microbial imprint on floral nectar sugar variation in a tropical plant community. Ann Bot (Oxford) 110:1173-1183

Carlson JE (2007) Male-biased nectar production in a protandrous herb matches predictions of sexual selection theory in plants. Amer J Bot 94:674-682

Carlson JE, Harms KE (2006) The evolution of gender-biased nectar production in hermaphroditic plants. Bot Rev 72:179-205

Cohen SA, Micheaud DP (1993) Synthesis of a fluorescent derivatizing reagent, 6 aminoquinolyl-N-hydroxysuccinimidyl carbamate, and its application for the analysis of hydrolysate amino acids via high performance liquid chromatography. Anal Biochem 211:279-287

Corbet SA (1978) Bees and the nectar of Echium vulgare. In: Richards AJ (ed) The pollination of flowers by insects. Academic Press, London, pp 21-29

Davila YC, Wardle GM (2002) Reproductive ecology of the Australian herb Trachymene incisa subsp. incisa (Apiaceae). Austral J Bot 50:619-626

Davila YC, Wardle GM (2007) Bee boys and fly girls: do pollinators prefer male or female umbels in protandrous parsnip, Trachymene incisa (Apiaceae)? Austral Ecol 32:798-807

de Vega C, Herrera CM (2013) Microorganisms transported by ants induce changes in floral nectar composition of an ant-pollinated plant. Amer J Bot 100:792-800

Ellis WN, Ellis-Adam AC (1993) To make a meadow it takes a clover and a bee: the entomophilous flora of NW Europe and its insects. Bijdrag Dierkunde 63:193-220 
Endress PK (2010) The evolution of floral biology in basal angiosperms. Phil Trans R Soc B 265:411-421

Erbar C, Leins P (2010) Nectaries in Apiales and related groups. Pl Divers Evol 128:269-295

Fahn A (2000) Structure and function of secretory cells. Advances Bot Res 31:37-75

Fetscher AE (2001) Resolution of male-female conflict in an hermaphrodite flower. Proc R Soc B 268:525-529

Gahan PB (1984) Plant histochemistry and cytochemistry: an introduction. Academic Press, London

Gunning BES, Hughes IE (1976) Quantative assessment of symplastic transport of pre-nectar into trichomes of Abutilon nectaries. Austral J Pl Physiol 3:619-637

Harder LD, Williams NM, Jordan CY, Nelson WA (2001) The effects of floral design and display on pollinator economics and pollen dispersal. In: Chittka L, Thomson JD (eds) Cognitive ecology of pollination. Cambridge University Press, New York, pp 297-317

Heil M (2011) Nectar: generation, regulation and ecological functions. Trends Pl Sci 16:191-200

Jensen WA (1962) Botanical histochemistry: principle and practice. W.H. Freeman \& Co., San Francisco

Koul AK, Hamal IA, Gupta SK (1989) Pollination mechanisms in Coriandrum sativum Linn. (Apiaceae). Proc Indian Acad Sci Pl Sci 99:509-515

Koul P, Sharma N, Koul AK (1993) Pollination biology of Apiaceae. Curr Sci 65:219-222

Kronestedt-Robards E, Robards AW (1991) Exocytosis in gland cells. In: Hawes CR, Coleman JOD, Coleman DE (eds) Endocytosis, exocytosis and vesicle traffic in plants. Cambridge University Press, Cambridge, pp 199-232

Langenberger MW, Davis AR (2002) Temporal changes in floral nectar production, reabsorption, and composition associated with dichogamy in annual caraway (Carum carvi; Apiaceae). Amer J Bot 89:1588-1598

Langenheim JH (2003) Plant resins: chemistry, evolution, ecology and ethnobotany. Timber Press, Portland

Lemoine R (2000) Sucrose transporters in plants: update on function and structure. Biochim Biophys Acta 1465:246-262

Lindsey AH, Bell CR (1985) Reproductive biology of Apiaceae. 2. Cryptic specialization and floral evolution in Thaspium and Zizia. Amer J Bot 72:231-247

Lloyd DG, Webb CJ (1986) The avoidance of interference between the presentation of pollen and stigmas in angiosperms. 1 . Dichogamy. New Zealand J Bot 24:135-162

Lovett Doust J, Harper JL (1980) The resource costs of gender and maternal support in an andromonoecious umbellifer, Smyrnium olusatrum L. New Phytol 85:251-264

Lunau K (2000) The ecology and evolution of visual pollen signals. Pl Syst Evol 222:89-111

Lunau K, Hofmann N, Valentin S (2005) Response of the hoverfly species Eristalis tenax towards floral dot guides with colour transition from red to yellow (Diptera: syrphidae). Entomol Gen 27:249-256

Mabberley DJ (2008) Mabberley's plant-book. A portable dictionary of plants, their classification and uses, 3rd edn. Cambridge University Press, Cambridge

Mallick SA (2001) Facultative dichogamy and reproductive assurance in partially protandrous plants. Oikos 95:533-536

Nepi M (2007) Nectary structure and ultrastructure. In: Nicolson S, Nepi M, Pacini E (eds) Nectaries and nectar. Springer, Dordrecht, pp 129-166

Nepi M (2014) Beyond nectar sweetness: the hidden ecological role of non-protein amino acids in nectar. J Ecol 102:108-115

Nepi M, Stpiczyńska M (2007) Nectar resorption and translocation in Cucurbita pepo L. and Platanthera chlorantha Custer (Rchb.). Pl Biol 9:93-100
Nepi M, Stpiczyńska M (2008) The complexity of nectar: secretion and resorption dynamically regulate nectar feature. Naturwissenshaften 95:117-184

Nepi M, Guarnieri M, Pacini E (2001) Nectar secretion, resorption, and sugar composition in male and female flowers of Cucurbita pepo. Int J Pl Sci 162:353-358

Nepi M, Bini L, Bianchi L, Puglia M, Abate M, Cai G (2011) Xylandegrading enzymes in male and female flower nectar of Cucurbita pepo. Ann Bot (Oxford) 108:521-527

Nepi M, von Anderkas P, Pacini E (2012) Sugary exudates in plant pollination. In: Vivanco JM, Baluska F (eds) Secretions and exudates in biological systems. Springer, Dordrecht, pp 155-186

Nicolson SW, Thornburg RW (2007) Nectar chemistry. In: Nicolson SW, Nepi M, Pacini E (eds) Nectaries and nectar. Springer, Dordrecht, pp 215-264

Niemirski R, Zych M (2011) Fly pollination of dichogamous Angelica sylvestris (Apiaceae): how (functionally) specialized can a (morphologically) generalized plant be? Pl Syst Evol 294:147-158

Olesen JM, Dupont YL, Ehlers BK, Hansen DM (2007) The openness of a flower and its number of flower-visitor species. Taxon $56: 729-736$

Ollerton J, Killick A, Lamborn E, Watts S, Whiston M (2007) Multiple meanings and modes: on the many ways to be a generalist flower. Taxon 56:717-728

Pacini E, Nepi M (2007) Nectar production and presentation. In: Nicolson S, Nepi M, Pacini E (eds) Nectaries and nectar. Springer, Dordrecht, pp 167-214

Pei NC, Luo ZL, Schlessman MA, Zhang DX (2011) Synchronized protandry and hermaphroditism in a tropical secondary forest tree, Schefflera heptaphylla (Araliaceae). Pl Syst Evol 296:29-39

Percival MS (1961) Types of nectar in angiosperms. New Phytol 60:235-281

Pérez-Bañón C, Petanidou T, Marcos-García MÁ (2007) Pollination in small islands by occasional visitors: the case of Daucus carota subsp. commutatus (Apiaceae) in the Columbretes archipelago. Spain. Pl Ecol 192:133-151

Petanidou T, van Laere A, Ellis NW, Smets E (2006) What shapes amino acid and sugar composition in Mediterranean floral nectars? Oikos 115:155-169

Ren G, Healy RA, Klyne AM, Horner HT, James MG, Thornburg RW (2007) Transient starch metabolism in ornamental tobacco floral nectaries regulates nectar composition and release. Pl Sci 173:277-290

Routley MB, Husband BC (2003) The effect of protandry on siring success in Chamerion angustifolium (Onagraceae) with different inflorescence sizes. Evolution 57:240-248

Routley MB, Bertin RI, Husband BC (2004) Correlated evolution of dichogamy and self-incompatibility: a phylogenetic perspective. Int J Pl Sci 165:983-993

Sargent R, Otto SP (2004) A phylogenetic analysis of pollination mode and the evolution of dichogamy in angiosperms. Evol Ecol Res 6:1183-1199

Schlessman MA, Underwood N, Watkins T, Graceffa LM, Cordray D (2004) Functions of staminate flowers in andromonoecious Pseudocymopterus montanus (Apiaceae, Apioideae). Pl Spec Biol 19:1-12

Stpiczyńska M (2003a) Nectar resorption in the spur of Platanthera chlorantha Custer (Rchb.) Orchidaceae-structural and microautoradiographic study. Pl Syst Evol 238:119-126

Stpiczyńska M (2003b) Incorporation of [3H] sucrose after the resorption of nectar from the spur of Platanthera chlorantha (Custer) Rchb. Can J Bot 81:927-932

Thomson JD, McKenna MA, Cruzan MB (1989) Temporal patterns of nectar and pollen production in Aralia hispida: implications for reproductive success. Ecology 70:1061-1068 
Vannette RL, Gauthier M-PL, Fukami T (2012) Nectar bacteria, but not yeast, weaken a plant-pollinator mutualism. Proc R Soc B 280:20122601

Vassiliev AE (2010) On the mechanism of nectar secretion: revisited. Ann Bot (Oxford) 105:349-354

Vezza M, Nepi M, Guarnieri M, Artese D, Rascio N, Pacini E (2006) Ivy (Hedera helix L.) flower nectar and nectary ecophysiology. Int J Pl Sci 167:519-527

Webb CJ (1981) Andromonoecism, protandry, and sexual selection in Umbelliferae. New Zealand J Bot 19:335-338

Williams LE, Lemoine R, Sauer N (2000) Sugar transporters in higher plants-a diversity of roles and complex regulation. Trends Pl Sci 5:283-290

Willmer P (2011) Pollination and floral ecology. Princeton University Press, Princeton, Oxford

Zdral B, Zych M (2012) Geographic pattern of specialization/ generalization in the pollination system of a protandrous umbellifer. In: 26th Annual Meeting of the Scandinavian Association of Pollination Ecologists, Skjærhalden Sjøbuer, Norway, pp 38
Zimmerman M (1988) Nectar production, flowering phenology, and strategies for pollination. In: Lovett Doust J, Lovett Doust L (eds) Plant reproductive ecology. Patterns and strategies. Oxford University Press, New York, pp 157-178

Zych M (2003) Pollination biology and phylogenetic position of two subspecies of Heracleum sphondylium L. PhD Thesis, University of Warsaw, Warsaw

Zych M (2007) On flower visitors and true pollinators: the case of protandrous Heracleum sphondylium L. (Apiaceae). Pl Syst Evol 263:159-179

Zych M, Niemczyk P, Niemirski R (2007) Umbellifers as potential keystone species in restoration projects. Acta Agrobot 60:45-49

Zych M, Stpiczyńska M, Roguz K (2013) Reproductive biology of the Red List species Polemonium caeruleum (Polemoniaceae). Bot J Linn Soc 173:92-107

Zych M, Michalska B, Krasicka-Korczyńska E (2014) Myophily in the critically endangered umbelliferous plant Ostericum palustre Besser (Apiaceae). Pl Syst Evol 300:187-196 